Connotas. Revista de crítica y teoría literarias 
CONNOTAS. REVISTA DE CRÍTICA Y TEORÍA LITERARIAS. Enero - diciembre 2013, es una publicación anual editada por la Universidad de Sonora, a través de la División de Humanidades y Bellas Artes, en el Departamento de Letras y Lingüística. Blvd. Luis Encinas y Blvd. Rosales s/n, Col. Centro, C.P. 83000, Hermosillo Sonora; Tel. (662) 2592 136, (662) 2592 157, <www.uson.mx>, <http://www.connotas.uson.mx, connotas@capomo.uson.mx>. Editor responsable: Rosario Fortino Corral Rodríguez. Reservas de Derechos al Uso Exclusivo núm. 04-2006-020714184900-102. ISSN: 18706630; ambos otorgados por el Instituto Nacional del Derecho de Autor. Licitud de Título núm. 13434 y de Contenido núm. 11007, otorgados por la Comisión Calificadora de Publicaciones y Revistas Ilustradas de la Secretaría de Gobernación. Este libro se publicó con el apoyo del Programa Integral de Fortalecimiento Institucional C/PIFI 2013-12934

Se autoriza la reproducción total o parcial de los contenidos de la presente publicación, siempre y cuando se acredite adecuadamente el origen de los mismos.

Datos de contacto para la publicación: División de Humanidades y Bellas Artes, Departamento de Letras y Lingüística; Apartado Postal 793, Col. Centro, C.P. 83000, Hermosillo, Sonora, México. Tels.: (662) 259-21-87, Tel-fax 212-55-29. Correo electrónico: connotas@capomo.uson.mx Página web: http://www.connotas.uson.mx 


\section{Connotas. Revista de crítica y teoría literarias}

Núm. 13, año 2013

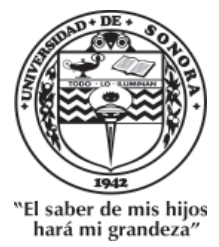


UNIVERSIDAD DE SONORA

RECTOR

Heriberto Grijalva Monteverde

VICERRECTORA

Arminda Guadalupe García de León Peñúñuri

Secretario General Académico

Enrique Fernando Velázquez Contreras

División de Humanidades y Bellas Artes

María Rita Plancarte Martínez

Departamento de Letras y LingÜística

Ana Bertha de la Vara Estrada

César Avilés Icedo

Rosa María Burrola Encinas

Fortino Corral Rodríguez

Leticia Martínez Figueroa

Jesús Abad Navarro Gálvez

Gabriel Osuna Osuna

María Rita Plancarte Martínez

DiRECTOR

Fortino Corral Rodríguez

Giuseppe Bellini

Consejo InTERnacional

Universidad de Milán

Carlos Pacheco

Luis Beltrán Almería

Universidad Simón Bolivar

Universidad de Zaragoza

Rafael Olea Franco

Helena Beristáin

El Colegio de México

Joan Oleza Simó

Universidad Nacional Autónoma de México

Universidad de Valencia

Raúl Bueno-Chávez

Dartmouth College

Julio Ortega

Evodio Escalante

Brown University

Luz Aurora Pimentel

Universidad Autónoma Metropolitana

Universidad Nacional Autónoma de México

Beatriz González-Stephan

Susana Reisz

Rice University

Aníbal González

The City University of New York.

José Carlos Rovira

Universidad de Alicante

Yale University

Aurelio González Pérez

Charles Tatum

El Colegio de México

Yvette Jiménez de Báez

The University of Arizona

Jorge Urrutia

El Colegio de México

Universidad Carlos III de Madrid

Nelson Osorio Tejeda

Universidad de Santiago de Chile

Emil Volek

Arizona State University 


\section{Índice}

\section{Artículos}

Una hermenéutica analógica para la literatura

Mauricio Beuchot Puente

La obra de Jorge Luis Borges durante la década de 1930: estudio de algunos elementos para la conformación de su poética en Discusión (1932)

Daniel Zavala Medina

Metáforas de la locura y la muerte en "Río subterráneo" de Inés Arredondo

Gabriel Osuna Osuna

La alteridad como vector de la construcción del yo: La muerte me da de Cristina Rivera Garza y El Gran Vidrio de Mario Bellatin Véronique Pitois Pallares

Uno soñaba que era rey de Enrique Serna: un espacio de contradicción Claudia Gidi

Una angustia compartida. Análisis de la voz narrativa en Mi hermano Carlos de Jorge López Páez

Jorge Antonio Muñoz Figueroa

De Los perros románticos y otros poemas de Roberto Bolaño Marina Martínez Andrade 
Las novelas del Crack, multiplicidad y superposición de mundos Ramón Alvarado Ruiz

La construcción del “otro" en la Relación de la jornada de Cíbola de Pedro Castañeda de Nájera

Guillermo Martínez Sotelo

Destino e historia en Margarita, está linda la mar de Sergio Ramírez

María Rita Plancarte Martínez

\section{Notas}

Identidad negada y mundo al revés en Santa María del Circo de David Toscana

César Avilés Icedo y María Elena González Borgaro 203

"El buen ejemplo" de Vicente Riva Palacio: la historia de un cuento

Marco Antonio Chavarín González

Organización descriptiva en Catarina de San Juan, princesa de la India y visionaria de Puebla

Silvia Guadalupe Alarcón Sánchez

Genealogías en Todo aqui es polvo de Esther Seligson. Lectura a partir de los epígrafes

Luz Elena Zamudio Rodríguez

\section{Reseñas}

Martha Elena Munguía Zatarain. La risa en la literatura mexicana (apuntes de poética)

Silvia Alicia Manzanilla Sosa 
Véronique Pitois-Pallares. El arte del fragmento: El Gran Vidrio de Mario Bellatin

Julio César Zárate Ramírez 255

Nicolás Kanellos. Hispanic Immigrant Literature: El sueño del retorno Josué Gutiérrez González

Dante Salgado. Brevísima relación de la idea de amor en Occidente Diana Vanessa Geraldo Camacho 271

Mara L. García. Paco Yunque: una mirada crítica Juan Paredes Carbonell 279

Abstracts 283

Résumés

Normas editoriales 



\title{
$\sim$ Notas $\sim$
}

\section{Identidad negada y mundo al revés en Santa María del Circo de David Toscana}

\author{
César Avilés Icedo* \\ María Elena GonzÁlez Borgaro*
}

Resumen:

La presente nota pretende asentar algunos apuntes sobre la novela Santa María del Circo desde tres perspectivas complementarias. La primera es de orden ideológica y antropológica y pretende enfocar el universo planteado en la novela como un universo equiparable a lo que se concibe como una comunidad imaginada, esta vez marcada por la parodia y la reversibilidad. La segunda es de orden narratológico y centra su atención en el compenente espacial del armado textual. La tercera aprovecha la fusión de las anteriores para proponer una lectura temática, donde se debate sobre la identidad particular de los personajes y como éstos se proyectan a una gran alegoría generalizable, escindida de las coordenadas internas de la obra.

Palabras clave:

Identidad, comunidades imaginadas, espacio, parodia y reversibilidad.

* Universidad de Sonora. 
Desde la primera lectura de Santa María del Circo (1998) del regiomontano David Toscana emergen varios temas, entre los cuales encuentra preeminencia el problema de la búsqueda de la identidad -individual y colectiva- de los seres humanos. El propósito de este trabajo es provocar la reflexión y brindar una hipótesis explicativa sobre las estrategias que hacen posible la representación de dicho problema en la novela. El análisis está guiado, en una primera instancia y a un nivel de semiótica intratextual, por la premisa de que entre la configuración de los personajes y la del espacio se establece una relación pródiga en significados que conduce a la propuesta éticoestética del texto. Como complemento de las conclusiones que arroja ese acercamiento, se explora la conexión que puede trazarse entre el mundo textual y otros aspectos de orden contextual.

La historia narrada en la novela crea un universo social atípico, paralelo a los mundos de los que se ocupan los discursos histórico, social y antropológico. La trama da cuenta de los avatares de un grupo de cirqueros que se instala en un pueblo fantasma que en su tiempo de bonanza albergó a los trabajadores de una mina y a sus familias. El grupo lo integran nueve personas -seis hombres y tres mujeres- que han decidido dejar la vida itinerante luego de que una de ellas -el copropietario del circo- tuviera una disputa con su socio/hermano, quien se ha marchado con los demás cirqueros y casi todos los animales con los que contaban.

El lugar elegido para establecerse es inhóspito, por lo cual la decisión de colonizarlo de nuevo es disparatada, como disparatada es también la organización social que los personajes acuerdan para la convivencia. Así, las reglas de interacción están lejos de lo que en las sociedades contemporáneas se entendería como "normales". Sin embargo, el lector puede extrapolar del mundo novelesco conductas y actitudes legibles desde un punto de vista realista. Por eso, independientemente de que el relato se sitúe en las coordenadas del absurdo, no se invalida la puesta en perspectiva de algunos temas y preocupaciones existenciales vigentes en los bordes del milenio.

En la narrativa anterior a las vanguardias, se instituía una correspondencia más o menos estable entre la identidad individual de los personajes y los espacios que éstos habitaban. Con el desarrollo his- 
tórico de la narrativa, la configuración de los espacios ha evolucionado en la relevancia que ésta tiene en la construcción de los personajes (cfr. Cabo Aseguinolaza). Las identidades se han vuelto problemáticas en la medida en que los espacios pasaron a mostrar la coexistencia de elementos de muy diversa índole. En las interpretaciones posmodernas de la sociedad y la literatura que se ocupa de ellas, el espacio no es uno solo -o al menos no unidimensional ni plano-, sino una conjunción compleja de espacios; por tanto, la identidad individual representada surge de la conjunción entre varias posibilidades de identidad. Es decir, si la sociedad moderna erigía identidades monolíticas e inamovibles, la posmodernidad dio lugar a identidades en conflicto (cfr. Alicia Llarena). Además, y como correlato de lo anterior, en estas sociedades el individuo se reconoce en un diálogo tenso entre lo que lo define esencialmente y los estímulos que le brinda la otredad (cfr. Gilberto Giménez).

En la evolución de las teorizaciones sociológicas y antropológicas aparece el concepto del "no lugar": "Si un lugar puede definirse como lugar de identidad, relacional e histórico, un espacio que no puede definirse ni como espacio de identidad ni como histórico, definirá un no lugar”, dice Marc Augé (83). Este teórico se refiere a los espacios superpoblados donde el individuo sólo se diferencia de los demás en la entrada y en la salida, aquellos donde sólo se requiere el carnet de identidad como boleto de ingreso, para luego perderse en el anonimato. Es posible aprovechar este constructo teórico para acercarse a la novela pues, a pesar de las diferencias obvias entre el espacio figurado en ella y aquellos a los que se refiere Augé, Santa María del Circo -el poblado, ya con ese nombre- puede interpretarse también como un no lugar en el cual los personajes ni siquiera requieren de un documento que acredite quiénes son, y su identidad se debate entre tres sustratos en conflicto: el primero es el que les confería su papel en el circo; el segundo implica la proyección de los deseos que tienen para sí como entes sociales: y, por último el que se deriva del oficio que les ha tocado desempeñar en la nueva sociedad.

Desde otra perspectiva, Santa María del Circo puede reconocerse como una comunidad imaginada en el sentido en que la define Benedict Anderson, en tanto que cumple suficientemente con las 
condiciones establecidas para ese constructo: fronteras finitas bien delimitadas, soberanía de sus habitantes para autorregirse, establecimiento de símbolos y de una historia (la mayor parte de las veces inventada bajo ciertos intereses), reconocimiento del territorio mediante un nombre propio, y fijación de una normativa que regula la convivencia entre los integrantes del núcleo social. Esta serie de características se asocia con la idea de "nación". Estableciendo relaciones entre estas características y las que presenta el microcosmos de la novela se encuentran coincidencias que sustentan la interpretación de que existe una correspondencia entre ambas. ${ }^{1}$ Los límites de Santa María del Circo están marcados por un cerro tras el cual se encuentra el caserío y una línea de magueyes "muy derecha". El grupo humano que lo puebla crea un sistema autónomo de gobierno, lejos de cualquier sistema político que interfiera en sus decisiones. En la búsqueda de un emblema nacional, surge la idea de establecer una "heráldica del pueblo" (que, por cierto, parodia muy de cerca la primera bandera de México: un estandarte con la virgen de Guadalupe bendiciendo animales de circo), y se plantea la necesidad de escribir una historia que proporcione una esencia comunitaria; a ello contribuye la creación y mantenimiento de un periódico para el registro y difusión de los acontecimientos importantes. El lugar no es reconocido como propio hasta que el nombre antiguo se sustituye por uno nuevo. Tácitamente se establecen reglas que obligan respeto a la autoridad (más notoriamente la eclesiástica) y desprecio a lo marginal (la prostitución); además, a pesar de las diferencias de cada personaje, a todos los motiva la idea de reinventarse negando un pasado que les resulta ingrato.

La caracterización tan especial que tiene la comunidad recién creada se va dando a medida que el grupo se consolida. La frase "El azar

${ }^{1}$ Es importante notar que hay un aspecto por el cual la comunidad de cirqueros se aparta del concepto de comunidad imaginada de Anderson, y es que en Santa María todos los habitantes se conocen. Pero este elemento, en este análisis, contribuye a resaltar la ironía que permea a la novela. 
es Dios" es tomada literalmente pues, mediante la insaculación por la cual se asignan los papeles que habrán de desempeñarse en la sociedad, los personajes se ubican dentro del lugar que jerárquicamente les corresponde. La razón para proponer los nuevos oficios no toma en cuenta los criterios que seguirían las comunidades reales, puesto que no se valoran las habilidades y capacidades necesarias para desempeñar la tarea que conlleva el oficio asignado. Así, el espacio empieza a configurarse como propicio para la escisión colectiva e individual. Tal escisión significa una ruptura no sólo con la sociedad a la que se pertenecía, sino que no existe respeto al sentido común; por ejemplo: el enano, que no recuerda ni una oración religiosa, es el sacerdote que debe oficiar misa; el hombre fuerte es la prostituta; la mujer barbuda es el médico... En el colmo del sinsentido en esta asignación de roles, el contorsionista debe desempeñar el papel de negro, y las obligaciones de esclavo que se le asignan se asumen por extensión metonímica a esa raza que históricamente llevó tal carga. Los oficios de afiladora o de periodista, que serían subsidiarios en un grupo social cuya prioridad es la de mantenerse con vida, son defendidos como imprescindibles por aquellas en quienes ha recaído la suerte de ejercerlos. Por otro lado, como se ha adelantado, los papeles que se asignan ni siquiera llegan a ser tales. Ya desde ahí está marcado el tono de la narración y el tipo de comunidad imaginada donde prima la idea de mundo al revés entre lo que es el mundo novelesco en relación con el referente real, a lo cual habremos de aludir de forma intermitente en este trabajo. ${ }^{2}$

En cuanto a los roles mencionados, desde el principio y casi hasta el final de la novela, éstos se imponen como algo inobjetable. Cuando el hombre fuerte incurre en lo que los integrantes del grupo con-

${ }^{2}$ A partir de los aportes bajtininianos, el término mundo al revés se consolidó como moneda de cambio entre los críticos, que aceptan este elemento como parte de una categoría cultural, el carnaval, extrapolable al análisis literario. La aparición de estos elementos que implican la sustitución de los papeles sociales por otros que los revierten, incide en el sentido general del texto: el mundo "normal" y sus valores son puestos en perspectiva con el fin de cuestionar su validez (cfr. Bajtin). 
sideran una falta de respeto al enano/sacerdote, ellos se manifiestan intimidantes hasta que el agresor se disculpa. Así, todos se apropian de su nueva personalidad social: el enano-sacerdote se instala en la iglesia, llama a misa y confiesa a sus feligreses; la barbuda-doctora atiende a los enfermos, el hombre bala-militar hace planes estratégicos y afina sus (irrisorias) armas para la supuesta defensa del lugar, el mago-agricultor siembra la tierra, el contorsionista-negro es su esclavo y desempeña las tareas que nadie desea, mientras que el hombre fuerte-puta atiende a los clientes con displicencia pero sin reparos. Esta discordancia entre las recientes identidades y las que habían sostenido previamente provoca el choque más obvio entre la identidad auto-asumida por los individuos y la que le asignan sus otros, porque la práctica prueba que estos sujetos no están habilitados ni capacitados para ejercer su profesión. La doctora no lo es más que de nombre y, debido a su incompetencia, el contorsionista que cae enfermo se agrava y muere.

En esta fractura entre lo que se es y lo que se pretende ser, la palabra propia es el sucedáneo del satisfactor ante las demandas del entorno. Como esa palabra es hueca, carente de peso específico, los discursos de los personajes no corresponden a realidades concretas, ya que se instalan en la megalomanía delirante. Además del elemento humorístico que de ahí se desprende, el texto evidencia la frustración que vive cada personaje por la discordancia entre lo que se desea y lo que se vive. La palabra ajena, por otro lado, es el arma principal para descalificar las pretensiones del otro, convertido casi siempre en oponente. Y ello es así tanto en el ámbito público como en el privado: en la palabra pública surgida del periódico que se hace circular clandestina pero efectivamente, se infama y se degrada; de forma similar, en la palabra privada los parlamentos están signados por el choque y la controversia inútil.

El enano es quien con más frecuencia debe sufrir la desacreditación a través de la palabra, en especial por la burla nominalista: los nombres que se le sugieren (Enanoski, el cíclope de Liliput, Dwarfonio, el Charro Chaparro y Nano el Enano) lo reducen aún más, condenándolo a extender su enanismo no sólo a su condición física sino a su aspiración social. No muy apartada de él en este as- 
pecto, la mujer barbuda -grotescamente llamada Barbarela- suplica casi que se recuerde su verdadero nombre, Angélica. Por eso el espectáculo que ambos proponen a la gerencia en su intento de que los recontraten -titulado "El nonato"- alcanza una relevancia significativa, ya que en la función se simularía un aborto de la mujer, de quien se extraería al enano envuelto de tal forma que sólo sacaría la cabeza. Él, cuyo nombre verdadero -Natanael- denota el nacimiento en año nuevo, deberá soportar la frustración constante porque siempre termina imponiéndose el concepto antitético al que propone para sí. En un intento extremo por elevarse literal y simbólicamente -su afán por crecer- el enano asciende (casi escala) hasta el monumento ecuestre ubicado en la plaza y lo monta asumiendo la postura que tenía el héroe a quien dicho monumento celebraba.

Estilísticamente, la novela muestra los choques entre los personajes, pues cada capítulo se narra desde la óptica que a cada uno corresponde. Con ello, la sucesión de episodios muestra siempre la confrontación de las miradas. Así, se contrasta la mirada del uno y de su otro, y el resultado es siempre el mismo: el otro condena al uno a la ignominia y aniquila cualquier posibilidad de concreción de la identidad pretendida. Así, todos están sujetos a un determinismo del cual no existe escapatoria posible.

Santa María es, al inicio -por lo que representa para el grupo-, un "adentro" donde encuentran cobijo los proyectos personales y se recupera una condición humana que el papel de cirqueros les había negado. Hércules patentiza este anhelo de sacudirse el estigma de animalidad fetichizando el excusado: "Ya no quiero hacer como animal $[. .$.$] quiero sentarme en un retrete como Dios manda". Por eso$ la reacción del gigantón al encontrar el mueble es de fascinación: sentado en ese retrete, se transporta a una niñez evocada como una etapa idílica. En este mismo sentido, Narcisa manifiesta el deseo compartido de humanizarse, de individualizarse y de identificarse con un sello que la reivindique del anonimato: "A mí me encantaría vivir bajo un techo firme, una dirección, un lugar a donde me lleguen cartas, un piso que se pueda barrer" (126).

En cada uno de los personajes, pues, el espacio nuevo representa la posibilidad de llenar ese vacío existencial y así contrarrestar la 
frustración vital de ser identificados por el defecto que más desean ocultar: el enanismo o los pelos, como ocurre con Natanael y Barbarela, respectivamente; o por un oficio que ya no se desea ejercer: ser la chica que el mago parte en dos (Narcisa) o continuar arriesgando la vida (el hombre bala).

Ese espacio entendido por ellos como el de la posibilidad, tiene una duración muy limitada: en cuanto se agotan las reservas alimenticias y el agua, ocurre la debacle. Por eso, en cuanto reaparece la mitad del circo que ha sobrevivido, todos ofrecen sus humildes servicios, sacrificando posiblemente lo que les queda de vida con tal de tener garantizado el magro sustento.

Y si el "adentro" es el espacio de la esperanza que pronto se difumina, el "afuera" es representado siempre como el espacio de la virtual agresión y de la burla segura. ${ }^{3}$ En él los personajes están expuestos al morbo y la insania de un público ansioso que, según lo especulado por Hércules, asoma desde las colinas que delimitan al pueblo, un público que:

pagó un boleto de precio exorbitante para atestiguar nuestro deterioro, viendo qué hacemos, si nos destruimos unos a otros, si nos morimos de sed o de hambre. Hacen apuestas sobre quién será el primero en caer. Seguramente ovacionaron quedamente cuando encontramos el agua "No están tan idiotas", habrán dicho, aunque quizá les decepcionó un poco no vernos desesperados, con la boca seca, bebiendo nuestros orines y volviéndonos locos como dicen que se vuelven los muertos de sed [...] Si el boleto fue caro, nadie se resignará a vernos felices en nuestro pueblito, como gente ordinaria, sembrando la tierra, yendo a misa los domingos y fiestas de guardar. (Santa María del Circo 127)

${ }^{3}$ Esta disposición binaria de "adentro" y "afuera”, para conceptualizar el espacio, es uno de los aspectos de la estructuración propuesta por Gabriel Zorán -citado por Mieke Bal (185). 
Al inicio de la aventura existía la voluntad de poder ocultar el deterioro, como dice Hércules; de escapar de la mirada despiadada de los de afuera, de esconder un cuerpo que ya ha perdido gracia y gallardía. La ambición de ser alguien se sublima hasta en el valor que el enano y la barbuda le atribuyen a la estatua ecuestre, pues para ellos la escultura es la concreción del homenaje a un antepasado de memoria gloriosa, que ambos se disputan para sí, en un intento de dignificarse ellos mismos en el amparo de un linaje ilustre. Sin embargo, paulatinamente aparece el desánimo, la convicción de que ese espacio es un espejismo, una falacia. $\mathrm{Y}$ aunque nadie se atreve a verbalizar su desilusión, el personaje que asume la función de periodista se convierte en portavoz de todos: "Es insostenible la idea de quedarnos a vivir en Santa María del Circo, ahora lo veo muy claro, aunque fue divertido jugar a los colonizadores" (126).

$Y$ es que, paulatinamente, las condiciones adversas se van imponiendo sobre los personajes: el espacio desértico resulta inhabitable, los artículos con los que habían logrado sobrevivir se agotan y, en el plano moral, las relaciones entre los cirqueros también se van desgastando. Con excepción de Narcisa, que se hace cargo del contorsionista enfermo hasta que muere, los demás personajes son invadidos por un sentimiento de mezquindad que se traduce en la negativa de concesiones para con los otros.

Finalmente, sobre los oficios adoptados se imponen las condiciones reales, las incapacidades: ni el cura sana las almas, ni la doctora cura los cuerpos. Los sueños de gran militar de Balo se desploman sin un ejército qué dirigir ni parque qué detonar. $Y$ en el proceso de deterioro la endogamia en Santa María del Circo produce sólo relaciones enajenadas, carentes de un sentido solidario. Las conversaciones son diálogos fallidos, monodiálogos acotados con un apunte amargo del interlocutor que, con la paciencia agotada, se niega a seguir escuchando. Y esto es así porque las figuraciones optimistas de la propia persona son obstaculizadas por la descalificación tajante del otro, como ocurre con la pregunta con la que el hombre fuerte interpela al mago: “EEl oficio de puta incluye escuchar tus necedades?”(135). Esta pregunta de Hércules es un ejemplo de cómo, cuando alguien expresa sus ambiciones y sus sueños en larguísimos parla- 
mentos cargados de un delirio ascendente, se le interrumpe con un golpe verbal que le para en seco sus ensoñaciones.

Igualmente frustrantes serán los intentos de construir la identidad proyectándose mediante modelos que los personajes han cultivado desde la infancia, como es el caso de Hércules o de Mandrake (el mago), quienes se conciben a sí mismos a imagen de Francisco Olegaroy y de Sandow, respectivamente. No tienen mejor destino aquellos que intentan el reconocimiento de quienes ellos creen ser mediante la optimización del acto circense que ejecutan, como la del hombre bala. Es de nuevo la mirada del otro la que les anticipa su fracaso, y es la imposición de quien detenta el poder (el dueño del circo) la que no sólo descalifica sino que reduce la aspiración del personaje a la identidad que a aquél conviene. El intento deriva en la humillación inmisericorde y a la reducción minimizante.

El final de la novela es contundente. Los sobrevivientes reciben con regocijo el regreso de lo que queda del circo. Los tres sujetos que han sido rechazados condensan la inutilidad de los esfuerzos de todo el grupo: Barbarela, sin control de sus actos, sigue a la caravana que marcha en retirada y camina como autómata por desiertos sin caminos, retando a la muerte; Hércules (gigantesco, pero puta) y Natanael (enano, pero sacerdote) se toman de la mano y se pierden en la oscuridad de la iglesia. La oscuridad descrita es tal que devora a la pareja; así, ambos aceptan y asumen fatalmente un destino sin esperanzas. En la desaparición de estos personajes en la oscuridad real y metafórica se consolida la anonimia, la negación total de cualquier posibilidad de ostentar una identidad. La antítesis física y por oficios de ambos, diluida en la oscuridad en la que se pierden, sintetiza la imposibilidad de obtener el reconocimiento más mínimo de la identidad anhelada. La parodia a Muerte sin fin (“Anda, putilla [...], vámonos al diablo"), que se encuentra en el último parlamento del enano, apostilla la propuesta ideológica que porta la novela. Los personajes no sólo están destinados a morir sino que, ya instalados en el cinismo, aceptan la condición extrema de la negación. Si en algún momento se establecían coincidencias entre las luchas por sobrevivir y sostener la identidad, la escena final disipa ambigüedades. Es la identidad y no el sostenimiento de 
la vida lo que importa. Los personajes existen, pero su dilución como personas sociales está consumada.

$\mathrm{Al}$ inicio de este análisis advertíamos que la trama no sigue los patrones de una narración realista; que las acciones de los personajes corresponden a una lógica que trastoca los valores del mensaje, y ello es así porque está vehiculado desde una perspectiva carnavalizante que presenta los objetos y las situaciones desde una postura estética/ ideológica del mundo al revés que estos tienen. Esta perspectiva genera el tono festivo que conlleva a un distanciamiento crítico de la realidad representada en el mundo novelesco. En una cadena de causas y efectos, los significados se impregnan de connotaciones que matizan el mensaje que se había desprendido en una interpretación directa de los sucesos que se narran. La decodificación de las claves comunicativas de la novela apunta a una interpretación que requiere del contexto para ser plena.

En una entrevista David Toscana advertía que el mensaje subterráneo que portaba la novela saltaba casi a la superficie:

es casi evidente que la novela [Santa María del Circo] representa una alegoría de la sociedad, tan evidente que los mismos personajes lo dicen: "vamos a fundar una sociedad". Tratan de ser gente útil, pero bueno, resulta lo que resulta. Pero sí, en esta novela, por más que yo diga que lo que quiero es hablar de cirqueros, es inevitable que los cirqueros se conviertan en símbolos de otras cosas. (101)

En este aserto se da cabida a las dos posibilidades de interpretación del texto: la directamente textual, lo cual llevaría a entender la novela sólo como un divertimento ingenioso pero relativamente inocuo e inane, o a estudiarla como un texto en el cual debe buscarse un sustrato de significación trascendente.

Lo que nuestra lectura nos deja es que, si bien es cierto que el mensaje trasciende el nivel intratextual, no es pertinente buscar un significado mediante supuestos develamientos de alegorías, símbolos o metáforas. Aquí resulta más plausible la analogía como estrategia para explicar la conexión entre texto y contexto. Desde tal punto 
de vista, la aventura de los cirqueros es análoga a la de individuos o grupos que se lanzan al cotidiano afán de pretender "ser" en un mundo que los repele o los condena al margen o al vacío. El muro de la negación de la identidad planteada en la novela es similar al de un mundo deshumanizado, en el que las cosas se han descarrilado de un tren orientado por la lógica y la razón. El sinsentido de las acciones de los cirqueros es acaso la hiperbolización del destino de los individuos o grupos que erran sus pasos en un caos apabullante. Con ello, la novela pone los reflectores sobre este caos desesperanzador, entendido como un signo distintivo de los tiempos que corren.

En la suerte de sus personajes, Santa María del Circo no es diferente de lo que muestran otras novelas del mismo autor. Tanto en El ejército iluminado como El último lector o Duelo por Manuel Pruneda, los personajes son seres desastrados, perdidos en propósitos mesiánicos o empresas descabelladas. En todos los casos, son seres derrotados por un entorno impermeable a sus pretensiones. En tal sentido, la novela que aquí hemos tratado muestra continuidad tanto en sus poéticas como en el aspecto ideológico que nutre los textos (cfr. Michael Abeyta).

Resumiendo, Santa María del Circo es un ejercicio escritural en el que las coordenadas del mundo planteado corresponden a las de una comunidad imaginada, pero en el accionar absurdo de sus personajes y en la configuración del espacio como un "no lugar", tal comunidad es un mundo al revés. En este universo signado por la inversión de papeles, brota un tipo de humor festivo que sirve al propósito final del texto: poner en perspectiva algunos de los componentes de la sociedad actual. De ello se desprende que, según la propuesta ético-estética del texto, las comunidades humanas y los individuos que las integran se pierden en el caos de la sinrazón y la nebulosa del anonimato.

\section{Bibliografía}

Abeyta, Michael. "El humor negro, la burla de la modernidad y la economía del libro en la narrativa de David Toscana". Revista de Crítica Literaria Latinoamericana 36. (2010): 415-436. 
Anderson, Benedict. Comunidades imaginadas. Reflexiones sobre el origen y la difusión del nacionalismo. Tr. Eduardo L. Suárez. México: F.C.E., 1993. Augé, Marc. Los no lugares. Espacios de anonimato. Una antropología de la sobremodernidad. Barcelona: Gedisa, 1992.

Avilés, Karla, "Entrevista con David Toscana, 'La literatura no tiene que ver con la geografía"”. Metapolítica. (2008): 100-101.

Bachelard, Gastón. La poética del espacio. Tr. Ernestina de Champourcín. México: F.C.E., 1975.

Bajtin, Mijail. La cultura popular en la Edad Media y el Renacimiento. El contexto de Francoise Rabelais. Versión de Julio Forcat y César Conroy. Madrid: Alianza Editorial, 2003 (1987).

$\mathrm{Bal}$, Mieke. Teoría de la narrativa. Una introducción a la narratología. $5^{\mathrm{a}}$. ed. Madrid: Cátedra, 1998.

Cabo Aseguinolaza, Fernando y María do Cebreiro. Manual de Literatura. Madrid: Castalia, 2006.

Cocco, Madeline. La identidad en tiempos de globalización. Comunidades imaginadas, representaciones colectivas y comunicación. Costa Rica: FLACSO, 2003.

Giménez, Gilberto. Estudios sobre las culturas y las identidades sociales. México: CONACULTA E ITESO, 2007.

_- "Materiales para una teoría de las identidades sociales". Instituto de Investigaciones Sociales de la UNAM. <http:// docentes2.uacj.mx/museodigital/cursos_2008/maru/ teoria_identidad_gimenez.pdf> [Consultado en marzo de 2012] Llarena, Alicia. Espacio, Identidad y literatura hispanoamericana. México: Universidad Autónoma de Sinaloa, 2007.

Pimentel, Luz Aurora. El espacio en la ficción. México: Siglo XXI, UNAM, 2001.

Slawinski, Janusz. "El espacio en la literatura: distinciones elementales y evidencias introductorias". Textos y contextos. Comp. y tr. Desiderio Navarro. La Habana: Arte y Literatura, 1989.

Toscana, David. Santa María del Circo: Random House Mondadori, 2004. 